\title{
An integer programming approach for Balancing and Scheduling in Extended Manufacturing Environment
}

\author{
${ }^{1}$ H. M. Emrul Kays, ${ }^{2}$ A.N.M. Karim \\ ${ }^{1,2}$ Dept. of Manufacturing and Materials Engineering \\ Kulliyah of Engineering \\ International Islamic University Malaysia, \\ Kuala Lumpur, Malaysia \\ ${ }^{1}$ h.m.emrul.kays@gmail.com \\ ${ }^{2}$ mustafizul@iium.edu.my
}

\author{
${ }^{1}$ M. L. R. Varela, ${ }^{2}$ A. S. Santos, ${ }^{3}$ A. M. Madureira \\ ${ }^{1,2}$ University of Minho, School of Engineering \\ Department of Production and Systems \\ ${ }^{3}$ GECAD Research Group, \\ Polytechnic Institute of Porto \\ ${ }^{1}$ leonilde@dps.uminho.pt \\ Id5249@alunos.uminho.pt, ${ }^{3}$ amd@isep.ipp.pt.
}

\begin{abstract}
In the fiercely competitive era induced by expansion of open business archetypes, the managerial aspects of Extended Manufacturing Environments (EMEs) are experiencing growing concerns. There is no scope of leaving a possible operational improvement unexplored. For enhanced operational efficiency and capacity utilization the balancing and scheduling problems of EMEs are, therefore, rightfully considered and an integer programme is proposed in this paper. The model is designed in a spread sheet and solved through What'sBest optimizer. The model capabilities is assessed through a test problem. The results have demonstrated that the model is capable of defining optimized production schedules for EMEs.
\end{abstract}

Keywords - Extended Manufacturing Environments; Integer Programming, Balancing and Scheduling Approaches.

\section{INTRODUCTION}

In this age of industrial globalization, to compete and sustain, manufacturers are incentivized to reconstruct and/or reformulate their production paradigm, from the context of open business archetypes [1, 2]. Due to the need of maintaining the global standards in the national industrial markets, providing the environmental friendly products and keeping the production cost low by maintaining the collaborative polices, the manufacturers have paved the way of changing their adopted production paradigm [1, 3, 4]. Moreover, the self-centered view of the mass and lean manufacturing business models are continuously pushing the manufacturer to look for a robust archetype that would help them to shift from closed-enterprises to a global openenterprise [5]. And for this reason the concept of extended enterprise, as well as agile and virtual manufacturing are justifiably considered in the literature. The concept of extended manufacturing system goes beyond the boundary of the traditional organizations and builds a well-defined alliance as well as the manufacturing networks among the focal company, suppliers, business partners, former competitors and customers [1]. Hence, instead of being a large conglomerate, this concept will bind the manufacturer to develop a global competing group [6]. In other words, this concept of extended manufacturing enterprise, which underneath in the supply chain management theories, refers to an entire supply network of a typical focal company $[7,8]$. Whereas the term supply network refers to the manufacturer-supplier relations featured by a set of assimilated strategy and/or the management policies followed by the focal companies for its selected suppliers [9].

However, managing the environment of extended enterprise is often viewed as much more intricate than the traditional one [5]. As, the EME concept emphasised on building a proper network among the focal company and all of its allies. In this regards, the importance of distributed scheduling for the extended manufacturing, which have drawn the attention of the researcher, cannot be denied any more [10]. The scheduling operations in the extended manufacturing environment can be attained from two different perspectives i.e. (a) developing the autonomous scheduling approach for the EME, (b) adopting the conventional scheduling approaches which are most commonly used in the mass and lean environment for the EME. Nevertheless though the conventional scheduling approaches aid the manufacturer in some extent; developing the mathematical model for balancing and scheduling the jobs for a typical extended manufacturing environment is expected to be more effective and advantageous.

In this paper we propose an integer programming approach for balancing and scheduling the jobs in a typical extended manufacturing environment. And the proposed model is solved through the What'sBest optimizer for attaining the appropriate decisions. The entire paper is organized as follows: a brief state of art is provided in section II, the relevant past literatures regarding to the scheduling approaches is provided in section III. Section IV defines the problems and Section V portrayed the developed mathematical model. The obtained computational results are provided in section VI. And some of the concluding remarks are summarized in section VII.

\section{EXTENDED MANUFACTURING ENVIRONMENT}

The term extended enterprise arised for the first time to represent the interactions and/or the information exchanges phenomena with an aim of reducing the costs of supply chain 
[11]. However, nowadays the view of the extended enterprise is more elaborated and most often defied as a well-structured business network where focal company, collaborators, suppliers, customers are worked together to achieve certain goals [12]. Besides, some of the researchers enlarge the perspective of the extended enterprise through the inclusion of the stake holders within the focal company's relationship [11].

Meanwhile, the term Extended Manufacturing Environments (EMEs) illustrates all the imperceptible (intangible) relations representing the entire manufacturing processes of an extended enterprises. Due to the presence of versatile entities, the extended manufacturing environments are viewed as more complicated than the conventional ones. In such an environment the focal and/or the core manufacturer produces the deliverable in cooperation with its suppliers and the collaborators through the geographically distributed manufacturing resources [13]. Hence, the complexity in the EMEs is arises frequently in distributing and managing the jobs within the geographically distributed manufacturing resources.

\section{BALANCING AND SCHEDUILING APPROACHES}

The balancing, scheduling and simultaneous balancing and scheduling concepts are most widely adopted in the conventional manufacturing environment with an aim of enhancing the productivity, satisfying the customer demand on time and maximize the resource utilizations. Among which, for satisfying the customer demand on time, the line balancing approach helps the decision makers to allocate a job to their corresponding workstations by featuring the precedence relations, number of workstations and/or cycle times[14]. Though the researchers imply the balancing concept frequently for the assembly lines, its application at various production environments is not very uncommon [15].

In 1955 Salveson adopted the balancing concept and formulated the first mathematical model for a typical assembly system [16]. Meanwhile in 1960, Bowmen proposed two different linear programming formulations for implying the balancing concepts in an assembly system. These models enable the decision makers to assign the jobs in the relevant workstations by considering the precedence and cycle time restrictions. Though the main aim of their proposed approaches is the same, the difference lies in the formulation. For example the first mathematical model follows the sequence position method whereas the second one follows the clock time [17].

However, in their research Gokcen and Erel (1997) reported that the inventory level of a typical manufacturing industry could increase significantly due to presence of imbalances. To solve this crucial problem, researchers adopted the balancing concept for their undertaken mixed model production system [18]. Besides, by featuring the resource utilization, Ağpak and Gökçen (2005) proposed a more realistic mathematical model for line balancing. In this approach, to increase the resource utilization the researches add an additional constraint that ensures the assignments of the jobs using same resources in a particular workstation [19]. By seeing the requirement of assignment restriction in deploying the balancing concepts, Scholl, Fliedner and Boysen (2010) defines and propose four different types of constraints namely task restriction, resource restrictions, work station restrictions and the distance restrictions [20]. Despite the assembly lines, the implementations of the balancing concepts in transfer lines are also not very uncommon in literature [21]. With the presence of evident benefits of the balancing concept in satisfying the on time customer demand, Sawik (2002) observe that the manufactures can attain competitive advantages by integrating the scheduling concepts with it [22].

In literature the mathematical models for operations scheduling are often found as autonomous entity or even proposed by integrating with the balancing concepts [23]. Since 1954, just after the publication of Johnson rules for twomachine flow-shop system, the autonomous scheduling issues have drawn the substantial attention of the researchers [24, 25]. For instance, in 1959, three distinctive IP based scheduling models are proposed in literature by Wagner, Bowman and Manne [26-28]. Most of these proposed autonomous scheduling approaches are also widely adopted in the manufacturing industries to sequence the jobs for the shared and/or the limited resources [29-32]. For such a case, the decision makers usually attempted to minimize any of the economic criteria i.e. makespan, service level, inventory level, resource utilization and etc. [32-34]. However, it is noteworthy that most of the IP based scheduling approaches proposed in the literature are mainly focused on disruptionfree environment [35].

A part from these autonomous scheduling approaches, nowadays it is also not very uncommon to find that application of the integrated balancing and scheduling concepts. The integrated line balancing and scheduling concepts helps the decision makers to satisfy on time customer demand and enhance the resource utilization by assigning the jobs to their corresponding workstations and sequence them accordingly [23]. For example Sawik (2002) formulated two distinguished mathematical model for integrated balancing and scheduling. The first models can balance and schedule a typical production flow line simultaneously whereas the second model performed it sequentially [22]. Apart from this, by considering the sequence dependent setup time, number of researchers integrating the balancing concept together with the scheduling $[23,36,37,38]$. However, though the line balancing and scheduling concepts are most commonly used for the manufacturing environment, its application is not limited to imply in the Extended Manufacturing Environment. As one of the crucial decision problem in the Extended Manufacturing Environment is to assign the jobs to its geographically distributed manufacturing resources and schedule the jobs for processing through each of the resources.

A number of researchers have already proposed to imply the software agent based scheduling approach for scheduling in an Extended Manufacturing Environment [39-41]. In this 
process multiple software are combined to execute the appropriate production plan. Besides, Santos et al. (2014) have endeavored to apply the conventional scheduling approaches in an Extended Manufacturing Environment. The researchers illustrated three possible scenarios of the extended manufacturing environment and apply the longest processing time rule, Released Longest Processing Time rule for assigning the jobs to the geographically distributed resources and the Johnson Algorithm for scheduling. However, due to the segregated implementation of the balancing and scheduling rules in their illustrated case studies, the optimal solutions may not always be attained. Moreover, the extended manufacturing environment may not always limit to two sequential machines. Therefore the adoption of the Johnson algorithm significantly limits the application of their proposed approach. To overcome these limitations, in this research, we propose an integer programming approach for simultaneous balancing and scheduling the jobs in an extended manufacturing environment.

\section{PROBLEM DEFINITION}

A typical extended manufacturing environment is considered in this research where a focal company intended to satisfy its customer demand by assigning the jobs to its geographically distributed manufacturing resources. To do so, usually a focal company faces two different types of decision problems i.e. (a) which job to be assigned to which resource and (b) what would be their processing sequences. A graphical illustration of an exemplary extended manufacturing environment is shown in Fig. 1.

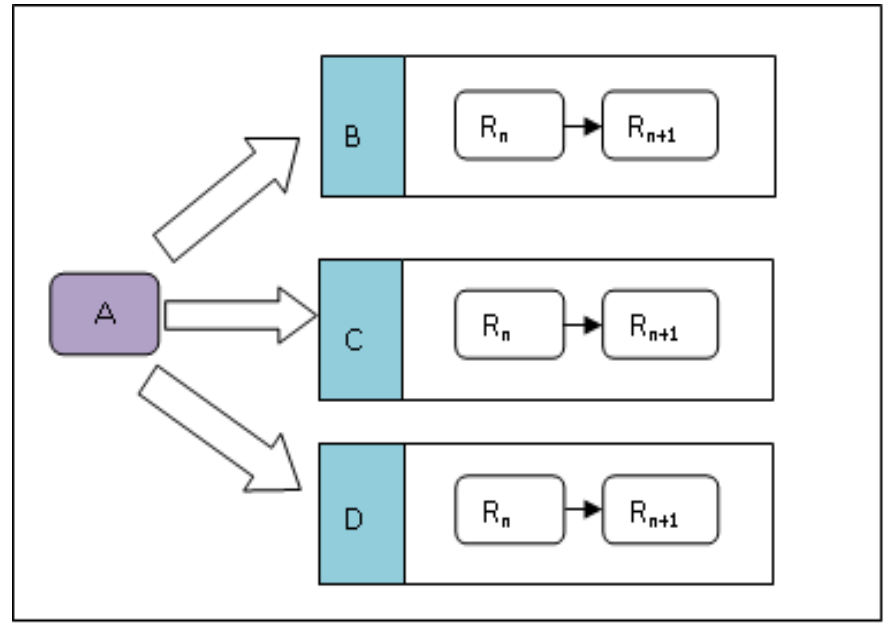

Figure 1. A Typical Extended manufacturing environment

In this typical extended manufacturing environment, a focal company-A has to distribute six jobs among three local companies (i.e. B, C, D) and/or the geographically distributed manufacturer in a manner that they can deliver the jobs to the customer within $36 \mathrm{t}$. $\mathrm{u}$. The companies B, C and D are capable to perform any of these six jobs and each of the job are needed to undergo two different operations and/or tasks through sequentially arranged resources $R_{n}$ and $R_{n+1}$ (two different resources). Therefore, the focal company is decided not to transfer the jobs after assigning it to a local company or in other words if any local company performed the first operations it must continue with the second one also. Under this condition, the company-A have to make the job assignment decisions and define their processing orders, so that the customer demand can be satisfied on time and the makespan is minimized. The jobs processing time of are given in Table I.

Table I. Processing time of the considered tasks

\begin{tabular}{|l|l|l|l|l|l|l|}
\cline { 2 - 7 } \multicolumn{1}{c|}{} & $\mathrm{J}_{1}$ & $\mathrm{~J}_{2}$ & $\mathrm{~J}_{3}$ & $\mathrm{~J}_{4}$ & $\mathrm{~J}_{5}$ & $\mathrm{~J}_{6}$ \\
\hline Tasks & $\mathrm{T}_{1}$ & $\mathrm{~T}_{2}$ & $\mathrm{~T}_{3}$ & $\mathrm{~T}_{4}$ & $\mathrm{~T}_{5}$ & $\mathrm{~T}_{6}$ \\
\hline Processing time & 6 & 15 & 12 & 12 & 18 & 3 \\
\hline Tasks & $\mathrm{T}_{7}$ & $\mathrm{~T}_{8}$ & $\mathrm{~T}_{9}$ & $\mathrm{~T}_{10}$ & $\mathrm{~T}_{11}$ & $\mathrm{~T}_{12}$ \\
\hline Processing time & 12 & 9 & 9 & 18 & 6 & 12 \\
\hline
\end{tabular}

\section{PROPOSED APPROACH}

A binary integer program is formulated and proposed in this section. This model is expected to help the focal company (A) in assigning the jobs to the local companies (B, C, D) and/or to the globally distributed resources. Not only jobs assignment, the proposed mathematical model is also enable the focal company to define the processing orders of the task simultaneously. The notations that are used in this mathematical model are given as follows:

\begin{tabular}{|c|c|}
\hline $\mathrm{N}$ & Total number of tasks \\
\hline$l$ & Number of local companies, $1=1,2, \ldots \ldots m$ \\
\hline i & Number of tasks, $\mathrm{i}=1,2,3, \ldots \ldots \mathrm{n}$ \\
\hline $\mathrm{j}$ & Number of jobs, $\mathrm{j}=1,2,3, \ldots \ldots \ldots \mathrm{k}$ \\
\hline $\mathrm{r}$ & Number of resources, $r=1,2,3 \ldots . . p$ \\
\hline $\mathrm{a}$ & The number of resource decision variables. \\
\hline$t_{i}$ & Processing time of task $\mathrm{i}$ where $\mathrm{i} \in \mathrm{SN}$ \\
\hline $\mathrm{T}_{l}$ & $\begin{array}{l}\text { Start time of tasks processing at any local } \\
\text { company } l\end{array}$ \\
\hline $\mathrm{C}_{\mathrm{i} l}$ & $\begin{array}{l}\text { Completion time of any task } \mathrm{i} \text { within each } \\
\text { of the local company } l\end{array}$ \\
\hline $\mathrm{C}_{\mathrm{i} \text { rs }}$ & $\begin{array}{l}\text { Completion time of any task } \mathrm{i} \text { at factory } l \text { in } \\
\text { resources } \mathrm{r} \text { for the sequence position } \mathrm{s}\end{array}$ \\
\hline $\mathrm{C}$ & Local cycle time and/or takt time \\
\hline $\mathrm{SN}$ & Set of all tasks and $\mathrm{N} \epsilon \mathrm{SN}$ \\
\hline $\mathrm{ST}_{\mathrm{j}}$ & $\begin{array}{l}\text { Set of tasks that are needed to accomplish } \\
\text { for each of the job and } \mathrm{ST}_{\mathrm{j}} \subset \mathrm{SN}\end{array}$ \\
\hline $\mathrm{ST}_{\mathrm{a}}$ & $\begin{array}{l}\text { Set of the numbers of particular decision } \\
\text { variables for assigning a task } i \text { at sequence } \\
\text { position } s \text { in a typical resource } r \text {. }\end{array}$ \\
\hline $\mathrm{ST}_{\mathrm{b}, \mathrm{c}}$ & Set of tasks that precedes a task \\
\hline
\end{tabular}

\section{Decision variables}

$\mathrm{x}_{\mathrm{i} l} \quad 1$ if task $\mathrm{i}$ is assigned to local company $l ; 0$ otherwise

$\mathrm{R}_{\mathrm{iars}} \quad 1$ if task $\mathrm{i}$ is processed in resource $\mathrm{r}$ first for sequence position $\mathrm{s}$; 0 otherwise 
Objective function

Maximize $\sum_{l=1}^{m}\left(C-C_{\max i l}\right) ; \forall i$

Subject to

$\sum_{l=1}^{m} x_{i l}=1, \forall i$

$\sum_{l=1}^{m}\left(\prod_{i \in S T j} x_{i l}\right) \leq 1$

$\sum_{l=1}^{m} l\left(x_{b l}\right)-\sum_{l=1}^{m} l\left(x_{c l}\right) \leq 0 ; \quad(b, c) \in S T_{b, c}$

$\left(C_{c l r s}-C_{b l r s}\right) \geq t_{c l} ; \quad(b, c) \in S T_{b, c}$

$C_{\text {ilrs }} \leq\left(T_{l}+C\right) ; \forall l$ and $i \in S T$

$C_{\text {ilrs }}=T_{l}+x_{i l} * t_{i l} * R_{\text {iars }} ; a \in S T_{a}$

$C_{i l r(s+1)}=T_{l}+x_{b l} * x_{c l} *$

$\left(t_{b l}+t_{c l}\right) * R_{\text {iar }(s+1)} ; a \in S T_{a}$

$C_{i l(r+1) s}=T_{j}+x_{(i-1) l} * x_{i l} *$

$\left(C_{(i-1) l r s}+t_{i l}\right) * R_{i a(r+1) s} ; a \in S T_{a}$

$C_{i l(r+1)(s+1)}=T_{l}+x_{b l} * x_{c l}$

$*\left(\operatorname{Max}\left(C_{i l(r+1) s}, C_{(i-1) l r s}\right)+t_{i l}\right)$

$* R_{i a(r+1)(s+1)} ; a \in S T_{a}$

$C_{\text {clrs }} \geq C_{\text {blrs }}$

$C_{\text {ilrs }}>0$

$C_{\max i l} \geq C_{\text {ilrs }}$

The objective function of the proposed model is to minimize the job completion time on each of the local manufacturer. In other word, the objective is to maximize the deviation in between the takt or local cycle time $(\mathrm{C})$ and the maximum task completion time $\left(\mathrm{C}_{\max } \mathrm{il}\right)$ for each of the local company. Constraint (2) ensures that a task can be assigned in any of the local company $l$ once and the partial assignment of the tasks is not allowed. As to accomplish each of the job $\mathrm{j}$ two sequential tasks need to be performed, hence the constraint (3) ensures that both of the tasks will be assigned to any of the particular local company. Constraint (4) and (5) express the tasks precedence relationships. Constraint (6) ensures that the completion time of the assigned tasks at any of the particular local company must be lower than the takt time set by the focal company. The equation (7) defines the compilation time of any tasks i within a local company $l$ at sequence position $s$ of a resource $r$. Whereas the equation (8), (9), (10) defines the completion time at sequence position $(\mathrm{S}+1)$ for the same resource $\mathrm{r}$, and for the successive resource $(\mathrm{r}+1)$ (at two different sequence position $\mathrm{S}$ and $\mathrm{S}+1$ ) respectively. The constraint (11) depicts that the completion time of any successor tasks will be higher than its predecessor.

Meanwhile constraint (12) represents that the compilation time of any of the tasks should be greater then 0 . And the constraint (13) ensures that the maximum task completion time within a typical local company should be higher or equal to any of the tasks completion time.

\section{COMPUTATIONAL RESULTS}

Initially, the proposed model is used to solve the balancing and scheduling problem of our illustrated case study in a typical Extended Manufacturing Environment. To do so, the developed model is designed in spread sheet and solved by the What'sBest optimizer on a workstation with an Intel ${ }^{\circledR}$ Core $^{\mathrm{TM}}$ i5 processor, 4 GB of RAM memory and Windows 7 64-bit as operating system. Some of the obtained results i.e. tasks assignment decisions, processing sequence, make spans are shown in following Table -II.

Table II. Results obtained by implementing the proposed model

\begin{tabular}{|l|l|l|l|}
\hline Factory & $\begin{array}{l}\text { Assigned } \\
\text { tasks }\end{array}$ & Task processing sequence & $\mathrm{C}_{\max }$ \\
\hline $\mathrm{B}$ & $\mathrm{T}_{2}, \mathrm{~T}_{6}$ & $\mathrm{~T}_{6}-\mathrm{T}_{2}$ & \\
& $\mathrm{~T}_{8}, \mathrm{~T}_{12}$ & $\mathrm{~T}_{12}-\mathrm{T}_{8}$ & 27 t.u. \\
\hline $\mathrm{C}$ & $\mathrm{T}_{4}, \mathrm{~T}_{5}$ & $\mathrm{~T}_{4}-\mathrm{T}_{5}$ & 36 t.u. \\
& $\mathrm{T}_{10}, \mathrm{~T}_{11}$ & $\mathrm{~T}_{10}-\mathrm{T}_{11}$ & \\
\hline $\mathrm{D}$ & $\mathrm{T}_{1}, \mathrm{~T}_{3}$ & $\mathrm{~T}_{1}-\mathrm{T}_{3}$ & $27 \mathrm{t} . \mathrm{u}$. \\
& $\mathrm{T}_{7}, \mathrm{~T}_{9}$ & $\mathrm{~T}_{7}-\mathrm{T}_{9}$ & \\
\hline
\end{tabular}

It can be seen from the table that the tasks $\mathrm{T}_{2}, \mathrm{~T}_{6}, \mathrm{~T}_{8}, \mathrm{~T}_{12}$ or in other words it is determined that the jobs $\mathrm{J}_{2}$ and $\mathrm{J}_{6}$ are assigned in factory B. Similarly, the tasks $T_{4}, T_{5}, T_{10}, T_{11}$ or the jobs $\mathrm{J}_{4}, \mathrm{~J}_{5}$ are assigned in the factory $\mathrm{C}$ and the tasks $\mathrm{T}_{1}$, $\mathrm{T} 3, \mathrm{~T} 7, \mathrm{~T} 9$ or the jobs $\mathrm{J}_{1}, \mathrm{~J}_{3}$ are assigned in factory D. Besides in factory $B$ the determined job processing sequence is $\mathrm{J}_{6}-\mathrm{J}_{2}$ whereas in factory $C$ it is $J_{4}-J_{5}$ and in factory $D$ it is $J_{1}-J_{3}$. This jobs assignment and its processing sequence led to the makespan of 27 t.u for factory B, of 36 t.u. for factory C and of $27 \mathrm{t} . \mathrm{u}$ for factory D. As the focal company has targeted the takt time of 36 t.u therefore it is observed that by maintaining this task assignment decision and their processing sequence the focal company can satisfy the customer demand on time. However, to assess the strength of the proposed mathematical model as well as the capability of attaining the optimal schedules, the model is implemented on a similar case study as represented in literature.

In this context, the case study (case-1) presented in the paper of the Santos et al. (2014) is considered and adapted to our selected problem by introducing some of the additional parameters [13]. For example, similar to our problem, in caselas presented by Santos et al. (2014), it is considered that the the GD (Global Decision) maker or broker attempted to assign and provide the processing sequence of six different jobs to three different factory and/or local decision makers. Though 
Table III. The obtained comparative results

\begin{tabular}{|c|c|c|c|c|c|c|c|c|c|c|}
\hline Problem & Jobs & Tasks & $\begin{array}{l}\text { Processing } \\
\text { time }\end{array}$ & Factories & $\begin{array}{l}\text { Assignment } \\
\text { decisions }\end{array}$ & $\begin{array}{l}\text { Processing } \\
\text { Sequence }\end{array}$ & Makespan & $\begin{array}{l}\text { Assignment } \\
\text { decisions } \\
\text { obtained }\end{array}$ & $\begin{array}{l}\text { Processing } \\
\text { Sequence } \\
\text { obtained }\end{array}$ & $\begin{array}{l}\text { Makespan } \\
\text { obtained }\end{array}$ \\
\hline \multirow{6}{*}{ Case-1 } & $\mathrm{J}_{1}$ & $\mathrm{~T}_{1}, \mathrm{~T}_{7}$ & 2,4 & \multirow{2}{*}{ Factory 1} & $\mathrm{~T}_{4}, \mathrm{~T}_{6}$ & $\mathrm{~T}_{6}-\mathrm{T}_{4}$ & \multirow{2}{*}{11 t.m.u. } & $\mathrm{T}_{2}, \mathrm{~T}_{6}$ & $\mathrm{~T}_{6}-\mathrm{T}_{2}$ & \multirow{2}{*}{9 t.m.u } \\
\hline & $\mathrm{J}_{2}$ & $\mathrm{~T}_{2}, \mathrm{~T}_{8}$ & 5,3 & & $\mathrm{~T}_{10}, \mathrm{~T}_{12}$ & $\mathrm{~T}_{12}-\mathrm{T}_{10}$ & & $\mathrm{~T}_{8}, \mathrm{~T}_{12}$ & $\mathrm{~T}_{12}-\mathrm{T}_{8}$ & \\
\hline & $\mathrm{J}_{3}$ & $\mathrm{~T}_{3}, \mathrm{~T}_{9}$ & 4,3 & \multirow{2}{*}{ Factory 2} & $\mathrm{~T}_{2}, \mathrm{~T}_{3}$ & $\mathrm{~T}_{2}-\mathrm{T}_{3}$ & \multirow{2}{*}{12 t.m.u. } & $\mathrm{T}_{4}, \mathrm{~T}_{5}$ & $\mathrm{~T}_{4}-\mathrm{T}_{5}$ & \multirow{2}{*}{12 t.m.u } \\
\hline & $\mathrm{J}_{4}$ & $\mathrm{~T}_{4}, \mathrm{~T}_{10}$ & 4,6 & & $\mathrm{~T}_{8}, \mathrm{~T}_{9}$ & $\mathrm{~T}_{8}-\mathrm{T}_{9}$ & & $\mathrm{~T}_{10}, \mathrm{~T}_{11}$ & $\mathrm{~T}_{10}-\mathrm{T}_{11}$ & \\
\hline & $\mathrm{J}_{5}$ & $\mathrm{~T}_{5}, \mathrm{~T}_{11}$ & 6,2 & \multirow{2}{*}{ Factory 3} & $\mathrm{~T}_{1}, \mathrm{~T}_{5}$ & $\mathrm{~T}_{1}-\mathrm{T}_{5}$ & \multirow{2}{*}{10 t.m.u. } & $\mathrm{T}_{1}, \mathrm{~T}_{3}$ & $\mathrm{~T}_{1}-\mathrm{T}_{3}$ & \multirow{2}{*}{9 t.m.u } \\
\hline & $\mathrm{J}_{6}$ & $\mathrm{~T}_{6}, \mathrm{~T}_{12}$ & 1,4 & & $\mathrm{~T}_{7}, \mathrm{~T}_{11}$ & $\mathrm{~T}_{7}-\mathrm{T}_{11}$ & & $\mathrm{~T}_{7}, \mathrm{~T}_{9}$ & $\mathrm{~T}_{7}-\mathrm{T}_{9}$ & \\
\hline
\end{tabular}

the researchers did not consider the takt time, to adapt our proposed approach we consider a takt time of 12 t.u. This consideration introduces a more realistic constraint that ensures all the tasks have to accomplish within 12 t.u.

The outputs obtained by implementing our proposed approach are compared to the outputs presented by Santos et al. (2014) and articulated in Table III. From table III it can be seen that, the tasks assignment obtained by our proposed model is different from the solutions proposed by Santos et al. (2014). For instance, Santos et al. (2014) proposed to assign job $\mathrm{J}_{4}$ and $\mathrm{J}_{6}$ in factory 1 , job $\mathrm{J}_{2}$ and $\mathrm{J}_{3}$ in factory 2 , job $\mathrm{J}_{5}$ and $\mathrm{J}_{6}$ in factory 3 ; whereas our proposed solution considers job $\mathrm{J}_{2}$ and $\mathrm{J}_{6}$ to assign in factory 1 , Job $\mathrm{J}_{4}$ and $\mathrm{J}_{5}$ in factory 2 , job $\mathrm{J}_{1}$ and $J_{3}$ in factory 3 . By changing the assignment and operations sequencing, our proposed mathematical model has shown its capabilities in reducing the makespan within each factory. This improvement is attained mainly due to our considerations of simultaneous job assignment and the tasks sequencing. This is illustrated in Fig. 2, where the blue bars represent the makespan obtain by our proposed IP model and the red bars represent the makespan presented by Santos et al. (2014). It is evident that our propose IP model performed better than the Santos et al. (2014) approach, for balancing and scheduling.

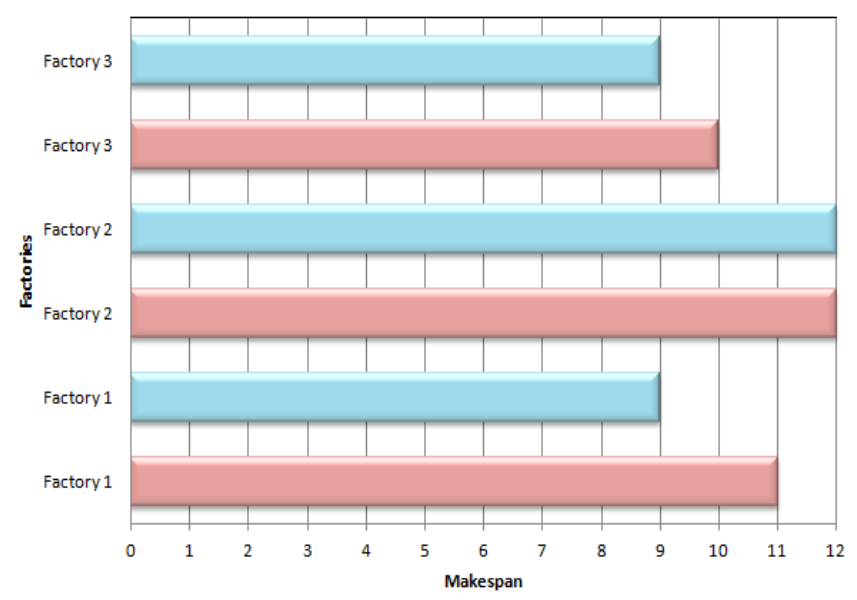

Figure 2. Comperative scenario of the makespan

\section{CONCLUSIONS}

To be agile and sustain in today's the fiercely competitive business, the extended manufacturing environments (EMEs) have drawn the attention of numerous researches as alternate robust production paradigms. Thus, managerial and operational challenges of the EMEs are becoming issues of serious concern. So to be responsive in managing and allocating the tasks as well as the resources in an effective and optimal manner, we worked out and solved in this paper a simultaneous balancing and scheduling problem of an EME. With the objective of attaining the optimal solution, an integer-programming model is proposed in this paper, the strength of which is assessed through a test problem presented in a published paper. By assessing the obtained result, it can be claimed that our proposed model has a better computational accuracy in minimizing the makespan compared to the conventional approaches of balancing and scheduling the extended manufacturing environment. Moreover, it has also been found that the developed model is capable to address the problem and can help the focal company in sequencing and assigning the jobs to the local companies and/or the collaborator in superior way. Thereby, the researchers are expecting to implement this proposed model in real Malaysian manufacturing environment. In future this model will be extended for large-scale problems having multi objectives and heuristics as well as metaheuristics approaches will also be proposed. Besides the influence of the What'sBest optimizer over the model performance in compared to the available ones will also be planed to assess in future. Additionally autonomous and reactive scheduling approaches may also be developed for handling disruptions occurring in any part of the supply chain of the EMEs.

\section{ACKNOWLEDGMENT}

This study has been conducted under FRGS project (FRGS14102-0343) funded by Ministry of Higher Education (MOHE), Malaysia. The authors are grateful to MOHE and Research Management Centre (RMC), International Islamic University Malaysia (IIUM) for their support. 


\section{REFERENCES}

[1] Browne, Jim, and Jiangang Zhang. "Extended and virtual enterprisessimilarities and differences." International Journal of Agile Management Systems 1, pp. 30-36, 1999

[2] Burt, Ronald S., N. Nohria, and R. G. Eccles. "Networks and organizations: structure, form and action", Harvard Business School Press, Boston, 1992.

[3] Windahl, Charlotta, Pierre Andersson, Christian Berggren, and Camilla Nehler. "Manufacturing firms and integrated solutions: characteristics and implications", European Journal of Innovation Management 7, pp. 218-228, 2004.

[4] Busby, J. S., and I-S. Fan. "The extended manufacturing enterprise: its nature and its needs", International journal of technology management 8, pp. 294-308, 1993.

[5] O'Neill, Henrique, and Peter Sackett. "The extended manufacturing enterprise paradigm", Management Decision 32, pp. 42-49, 1994.

[6] Frederix, Florent. "An extended enterprise planning methodology for the discrete manufacturing industry", European Journal of Operational Research 129, pp. 317-325, 2001

[7] Lamming, Richard. "Beyond partnership: strategies for innovation and lean supply”, London: Prentice Hall, 1993.

[8] Harland, Christine M. "Supply chain management: relationships, chains and networks", British Journal of management 7, pp. 63-80, 1996

[9] Ir, Rick Middel, Louis Brennan, David Coghlan, and Paul Coughlan. "The application of action learning and action research in collaborative improvement within the extended manufacturing enterprise", In Research methodologies in supply chain management, Physica-Verlag HD, pp. 365-380, 2005.

[10] Varela, Maria Leonilde R., Goran D. Putnik, and Maria Manuela CruzCunha. "Web-based Technologies Integration for Distributed Manufacturing Scheduling in a Virtual Enterprise", International Journal of Web Portals (IJWP) 4, pp. 19-34, 2012.

[11] Sachs, Sybille. "Managing the extended enterprise: the new stakeholder view", California management review 45, pp. 6-28, 2002.

[12] Boardman, John T., and Ben T. Clegg. "Structured engagement in the extended enterprise", International Journal of Operations \& Production Management 21, pp. 795-811, 2001.

[13] Santos, A. S., M. L. R. Varela, G. D. Putnik, and A. M. Madureira. "Alternative approaches analysis for scheduling in an Extended Manufacturing Environment", In Nature and Biologically Inspired Computing (NaBIC), 2014 Sixth World Congress on, pp. 97-102. IEEE, 2014.

[14] Sabuncuoglu, Ihsan, Erdal Erel, and M. Tanyer. "Assembly line balancing using genetic algorithms", Journal of Intelligent Manufacturing 11, pp. 295-310, 2000.

[15] Guschinskaya, Olga, and Alexandre Dolgui. "Comparison of exact and heuristic methods for a transfer line balancing problem", International Journal of Production Economics 120, pp. 276-286, 2009.

[16] Salveson, Melvin E. "The assembly line balancing problem", Journal of Industrial Engineering 6, pp. 18-25, 1955.

[17] Bowman, Edward H. "Assembly-line balancing by linear programming", Operations Research 8, pp. 385-389, 1960.

[18] Gokcen, Hadi, and Erdal Erel. "A goal programming approach to mixedmodel assembly line balancing problem", International Journal of Production Economics 48, pp. 177-185, 1997.

[19] Ağpak, Kürşad, and Hadi Gökçen. "Assembly line balancing: Two resource constrained cases", International Journal of Production Economics 96, pp. 129-140, 2005.

[20] Scholl, Armin, Malte Fliedner, and Nils Boysen. "Absalom: Balancing assembly lines with assignment restrictions", European Journal of Operational Research 200,pp. 688-701, 2010.

[21] Guschinskaya, Olga, and Alexandre Dolgui. "Comparison of exact and heuristic methods for a transfer line balancing problem", International Journal of Production Economics 120, pp. 276-286, 2009.

[22] Sawik, Tadeusz. "Monolithic vs. hierarchical balancing and scheduling of a flexible assembly line", European Journal of Operational Research 143, pp. 115-124, 2002.

[23] Kays, HM Emrul, A. N. M. Karim, M. Abdesselam, Muataz HF Al Hazza, and R. A. Sarker. "Formulation of Integer Programming Model for Balancing and Scheduling of Production Line Having Shared Resources", Proceedings of the 2014 International Conference on Industrial Engineering and Operations Management, Bali, Indonesia, January 7 - 9, (2014), pp. 19982007,2014

[24] Gomes, Marta Castilho, Ana Paula Barbosa-Póvoa, and Augusto Queiroz Novais. "Reactive scheduling in a make-to-order flexible job shop with re- entrant process and assembly: a mathematical programming approach", International Journal of Production Research 51, pp. 5120-5141, 2013.

[25] Stafford, E. F., F. T. Tseng, and J. N. D. Gupta. "Comparative evaluation of MILP flowshop models", Journal of the Operational Research Society 56, pp. 88-101, 2005

[26] Wagner, Harvey M. "An integer linear - programming model for machine scheduling", Naval Research Logistics Quarterly 6, pp. 131-140, 1959 .

[27] Bowman, Edward H. "The schedule-sequencing problem", Operations Research 7, pp. 621-624, 1959.

[28] Manne, Alan S. "On the job-shop scheduling problem", Operations Research 8, pp. 219-223, 1960.

[29] Choi, S. H., and K. Wang. "Flexible flow shop scheduling with stochastic processing times: A decomposition-based approach", Computers \& Industrial Engineering 63, pp. 362-373, 2012.

[30] Floudas, Christodoulos A., and Xiaoxia Lin. "Mixed integer linear programming in process scheduling: Modeling, algorithms, and applications", Annals of Operations Research 139, pp. 131-162, 2005.

[31] Harjunkoski, Iiro, Christos T. Maravelias, Peter Bongers, Pedro M. Castro, Sebastian Engell, Ignacio E. Grossmann, John Hooker, Carlos Méndez, Guido Sand, and John Wassick. "Scope for industrial applications of production scheduling models and solution methods", Computers \& Chemical Engineering 62, pp. 161-193, 2014.

[32] Reklaitis, Gintaras V. "Overview of scheduling and planning of batch process operations", In Batch processing systems engineering, Springer Berlin Heidelberg, pp. 660-705. 1996.

[33] Rabiee, M., Reza Sadeghi Rad, M. Mazinani, and R. Shafaei. "An intelligent hybrid meta-heuristic for solving a case of no-wait two-stage flexible flow shop scheduling problem with unrelated parallel machines", The International Journal of Advanced Manufacturing Technology 71, pp. 12291245, 2014.

[34] Yenisey, Mehmet Mutlu, and Betul Yagmahan. "Multi-objective permutation flow shop scheduling problem: Literature review, classification and current trends", Omega 45, pp. 119-135, 2014.

[35] Méndez, C. A., G. P. Henning, and J. Cerdá. "An MILP continuous-time approach to short-term scheduling of resource-constrained multistage flowshop batch facilities", Computers \& Chemical Engineering 25, pp. 701 711, 2001.

[36] Andres, Carlos, Cristobal Miralles, and Rafael Pastor. "Balancing and scheduling tasks in assembly lines with sequence-dependent setup times", European Journal of Operational Research 187, pp. 1212-1223, 2008.

[37] Karabat1, Selçuk, and Serpil Sayın. "Assembly line balancing in a mixedmodel sequencing environment with synchronous transfers", European Journal of Operational Research 149, pp. 417-429, 2003.

[38] Scholl, Armin, Nils Boysen, and Malte Fliedner. "The assembly line balancing and scheduling problem with sequence-dependent setup times: problem extension, model formulation and efficient heuristics", OR spectrum 35, pp. 291-320, 2013.

[39] Carvalho, J.; Varela, M.L.R.; Putnik, G.D.; Hernández, J.; Ribeiro, R.A., A Web-Based Decision Support System for Supply Chain Operations Management Towards an Integrated Framework. Decision Support Systems III - Impact of Decision Support Systems for Global Environments, Lecture Notes in Business Information Processing (LNBIP), Springer International Publishing, 104-117, 2014, (ISBN: 978-3-319-11364-7). http://www.scimagojr.com/journalsearch.php?q=17500155101\&tip=sid\&clea $\mathrm{n}=0$

[40] Arrais-Castro, A., M. L. R. Varela, R. A. Ribeiro, and F. C. C. Dargam. "Negotiation Platform for Collaborative Networked Organizations using a Dynamic Multi-Criteria Decision Model." In GDN2014, Joint International Conference of the INFORMS GDN Section and the EURO Working Group on DSS Toulouse. 2014.

http://www.irit.fr/gdn2014/contenu/program/GDN2014-Proceedings.pdf

[41] Madureira, Ana, and Joaquim Santos. "Proposal of multi-agent based model for dynamic scheduling in manufacturing", WSEAS Transactions on Information Science and Applications 2, pp. 600-605, 2005. 